\title{
AS MEMÓRIAS EM IMAGENS E RELATOS PESSOAIS: EXPERIÊNCIAS NO ENSINO SUPERIOR
}

Angelica Neumaier ${ }^{1}$

A minha prática enquanto artista/professorado Curso de Artes Visuais Bacharelado e Licenciatura, da Unesc na grande maioria das vezes foi influenciada por minha poética. Trago para a sala de aula experiências práticas vividas enquanto artista visual/pesquisadora. Durante minha docência realizei diversas experiências com relação à memória e à memória patrimonial nas disciplinas que ministro no Curso como Gravura e Pesquisa - Bacharelado/Licenciatura e Serigrafia e Pesquisa - Licenciatura.

Acredito que a pesquisa deve permear o processo educativo, instigando 0 aluno a pensar no seu processo formativo e na sua futura atuação, na medida em que a sua formação é problematizada e questionada, o educando torna-se parte integrante da transformação que poderá acontecer no momento de sua atuação como professor/pesquisador. Segundo Catani (2006, p.16):

As últimas décadas do século XX ressaltaram a importância do histórico dos agentes (professores ou alunos) dos processos pedagógicos, no campo educacional e em especial no domínio da formação de professores. De fato, o foco da atenção passou a recair sobre a compreensão da vida, das experiências e das relações estabelecidas pelos sujeitos em seu percurso de formação. Progressivamente, a noção de 'histórias de vida', importante desde há muito para as ciências sociais e a história, passa a ter um lugar de destaque nos estudos sobre a formação de professores.

Uma proposta artística e de pesquisa patrimonial relacionada com a gravura foi desenvolvida pela acadêmica Ana Paula Fernandes, acadêmica do Curso de licenciatura em Artes Visuais da Unesc, no município de Cocal do Sul, SC, no ano de 2011, através da busca de imagens da arquitetura e monumentos históricos da cidade, a acadêmica realizou três xilogravuras ${ }^{2}$ (gravura em madeira) realizando uma oficina de gravura para a comunidade.

\footnotetext{
${ }^{1}$ Universidade do Extremo Sul Catarinense - UNESC. E-mail: ann@unesc.net

${ }^{2}$ Xilografia ou xilogravura - Técnica de impressão em relevo realizada sobre madeira, em geral de árvores de fruto ou buxo. As partes escavadas pelas ferramentas constituem as zonas brancas,
} 
No ano de 2013, uma nova proposta originária da disciplina de Serigrafia e Pesquisa do Curso de Artes Visuais - UNESC, buscou-seno relato dos acadêmicos suas "Memórias da Escola" realizado através de um questionário,resultando em 23 serigrafias ${ }^{3}$ no formato $A 3(29 \times 42 \mathrm{~cm})$, visando conhecer o percurso dos mesmos a partir desua escola e quais eram suas memórias e lembranças de sua formação. De acordo com Catani (2006, p.17):

Estudos acerca da memória e história da profissão docente também passaram a incluir, dados da história dos sujeitos-professores e suas experiências de formação e de trabalho. A reconstrução destas histórias de vida se faz por meio de entrevistas, depoimentos ou narrativas autobiográficas escritas.

Os alunos respondem a um questionário sobre quais memórias eles trazem do ensino da arte, quais linguagens artísticas eram trabalhadas na escola, e quais lembranças eles trazem de sua vida escolar, confirmando que:

[...]descobre-se que o processo de refazer percursos, relatar experiências, descobrir relações entre as várias etapas formadoras de nossa própria vida - como as relações familiares, a escolarização, leituras, valores assimilados, condição de gênero e outros - torna-se por si só um processo "formador" que gera novas interpretações de nós mesmos e influencia as ações pedagógicas que desenvolvemos. O esforço de compreensão das próprias relações com a escola, com os professores, o conhecido, 0 desconhecido, a leitura, a escrita e o desejo de aprender despertados pelos relatos sobre si teria, então, um efeito educativo para os professores. Com base nesta constatação fica mais fácil identificar e compreender, a partir da história pessoal, as escolhas de cada um e a construção de seu estilo didático. A formação de alunos não dispensará um ouvido atento às histórias de aprendizagem de cada um.(CATANI, 2006, p.18).

Novamente no primeiro semestre de 2015, é realizada uma pesquisa através de questionário (no total de 37 questionários respondidos) na disciplina de Gravura, com as turmas de licenciatura e bacharelado, sendo a pesquisa da 'Memória da Escola', na turma de licenciatura, e a pesquisa sobre 'Memórias

enquanto as partes intactas receberão a tinta por meio de um rolo entintado. (CATAFAL, 2003, p.159).

${ }^{3}$ A serigrafia (ou estampado a lionesa) pode ser considerada como uma evolução do processo de estêncil que tem sido praticado no Japão desde o século VIII. É uma das técnicas de estampagem mais versáteis e pode ser usada para produzir algo com simples estênceis ou impressões por reserva de ceras até complexas imagens fotográficas. Não é difícil de dominar e pode ser usado com muitos tipos de corantes e pigmentos e técnicas de efeitos de corrosão, de reserva ou de textura. (WELLS, 1998, p.97). 
Pessoais' na turma do bacharelado. As gravuras foram realizadas em pequenos formatose colocadas no suporte de um'marmitex', utilizando a linguagem da serigrafia com a ideia dealimento, com o título 'O que alimenta sua memória? lugares-corpo x lugares-memória',sendo uma atividade interdisciplinar com a disciplina de Escultura e Pesquisa, do Curso de Artes Visuais - UNESC. Foi realizada uma exposição mostrando os resultados para a reabertura da nova Biblioteca da Unesc, entre os dias 30 de junho e 6 de Julho de 2015, no hall da nova biblioteca. De acordo com Catani (2006, p.16):

\begin{abstract}
Com a valorização do papel do sujeito na compreensão dos processos sociais e históricos, o reconhecimento do que os sujeitos dizem ou escrevem acerca de suas próprias experiências de formação passou a inspirar estudos sobre a questão. Desse modo, foram propostas situações para formar professores (ou aqueles que se preparam para sê-lo), em que eles pudessem refletir sobre suas experiências de escolarização, relações com a leitura, a escrita e com conhecimentos disciplinares específicos.

Tais iniciativas se multiplicam, na década de 1980, em diversos países como França (Gaston Pineau), Suíça (Christine Josse e Pierre Dominicé) e Portugal (Antônio Nóvoa). No Brasil, especialmente na Faculdade de Educação da USP, o trabalho nessa direção começou a se difundir no início da década de 1990. Foram propostas ações de formação desse tipo no curso de Pedagogia, Licenciatura, e também em cursos com docentes da rede pública de ensino.
\end{abstract}

Abbagnano (2007, p.668) comenta que a memória é a "possibilidade de evocar, quando necessário, o conhecimento passado e de torná-lo atual ou presente: é propriamente a recordação."

Trouxe como problema de pesquisa: Como a memória em forma de imagens e relatos pessoais contribui para pensar o processo de formação do professor e sua futura atuação?. Segundo Catani (2006, p.17):

Quando os professores falam ou escrevem sobre a experiência de formação e de trabalho, podem indicar aspectos ligados às relações que mantém ou ao significado que atribuem ao que vivem. Esse processo permite compreender melhor o que está em jogo na vida educacional e no trabalho docente. Falam de suas dificuldades, do seu sucesso, das alternativas que descobrem para solucionar os desafios do ensino. Os esclarecimentos que se obtêm ao se desvelarem as lembranças e as histórias dos professores dizem respeito justamente às tentativas, acertos, desvios, e invenções que cada um constrói no cotidiano, algo que é quase impossível obter por outras fontes. 
Tendo como objetivos conhecer, recolher e fundamentar os relatos de 'memórias de formação'4 ou de 'memórias autobiográficas' dos sujeitos envolvidos em educação, realizando um percurso em torno das narrativas particulares, realizouse a partir das imagens trazidas pelos entrevistados, com o auxílio dos meios de expressão de uma linguagem artística como a gravura em suas várias técnicas (a xilogravura, a serigrafia, etc) gravuras/objetos artísticos que foram impressos e trabalhados compondo assim, um acervo de gravuras e memórias impressas em que o acadêmico visualizou sua produção advinda de sua memória pessoal.

A partir das narrativas trazidas pelos acadêmicos de suas memórias de formação foi possível problematizar suas experiências durante seu tempo de escola, suas vivências, desafios encontrados, que puderam ser discutidos em grupo e assim revelando suas experiências como potencial de reflexão. Isso remete para a afirmação de Catani (2006, p. 21), quando ela afirma que:

De fato, trabalhar na produção escrita de narrativas em primeira pessoa e na sua partilha oral num momento subsequente assegura a compreensão de si de suas práticas em confronto com as percepções dos outros, que resultam em reconfigurações do conhecimento da própria história. 0 escrever sobre si e tornar esse ato público envolve uma espécie de "exercício de astuciosa franqueza". Gerenciar, em cada momento, o dizível, o indizível e o partilhável situa o sujeito num espaço privilegiado para a reinvenção de si e dos seus modos de atuar no trabalho formador.

Catani (2006, p.17) comenta ainda que:

A memória é um elemento fundamental na reconstrução das "histórias de vida" e nas 'narrativas autobiográficas'. Ao se recorrer a essa fonte vale a pena levar em conta como o lembrar e o esquecer compõem a dinâmica da memória. Muitos autores têm mostrado como se dão os processos de constituição de memórias individuais e coletivas e a forma pela qual o contexto social influencia essas memórias, ou seja, quanto dependemos da vida em sociedade e dos fatos que nela ocorrem para o registro de nossas lembranças. E, também, até que ponto esses fatos determinam uma maneira própria de recordar.

As memórias evocadas pelos acadêmicos tanto memórias pessoais como memórias de seu tempo de escola trazem em seus relatos a possibilidade de conhecermos suas histórias de vida e de sua trajetória escolar, elementos muito

\footnotetext{
${ }^{4}$ CATANI, Denise. B. A reconstrução da prática educativa a partir da narrativa autobiográfica do professor. Instituto Arte na Escola. São Paulo: Cultura Acadêmica, 2006, p.18. ${ }^{5}$ Ibdem.
} 
ricos para o professor/pesquisador. Transformar essas memórias em imagens é o desafio que torna a memória perene em forma de objetos artísticos. Sendo assim:

O que se propõe é a reelaboração de registros de memória e a construção de narrativas autobiográficas nas quais as pessoas retomam os fios condutores de suas experiências para tecerem considerações acerca de si mesmas e dos seus modos de ensinar e aprender.(CATANI, 2006, p.18).

Uma vez que é:

A partir da história pessoal, as escolhas de cada um e a construção de seu estilo didático podemostornar o processo formador mais próximo do sujeito, essa concepção parte do reconhecimento de que a educação se assemelha, de fato, a outras intervenções das ciências humanas, ou seja, a outros processos que buscam informações sobre as pessoas para melhorar suas condições de vida, diminuir seu sofrimento, aumentar sua compreensão. (CATANI, 2006, p.18).

Através da pesquisa e problematização a partir das narrativas pessoais/partilha das experiências e memórias do seu tempo de escola com imagens da escola trazidas pelos acadêmicos, foram produzidas gravuras e serigrafias, compondo um acervo artístico único, criado pelo lembrar e narrar de cada futuro professor/pesquisador. Finaliza Catani (2006, p.21) argumentando que: :

Consideramos que esse modo de constituir a formação inicial ou continua de professores (pelo envolvimento dos sujeitos ou pelas alterações na percepção de si que ele provoca) permite justamente que se compreendam as múltiplas relações entre "a realidade externa e seu impacto interno" reveladas em suas formas de agir, ressaltando a importância dos relatos de práticas como elementos capazes de assegurar novas disposições individuais e coletivas para a ação pedagógica".

A partir da prática de se construir uma produção de escrita das narrativas em primeira pessoa e na sua apresentação oral resulta na compreensão de si mesmo e de suas práticas em sala de aula.

\section{REFERÊNCIAS}

ABBAGNANO, Nicola. Dicionário de filosofia. São Paulo: Martins Fontes, 2007. 
CATAFAL, Jordi; OLIVA, Clara. A gravura. Lisboa: Estampa, 2003.

CATANI, Denise B. A reconstrução da prática educativa a partir da narrativa autobiográfica do professor.Instituto Arte na Escola. São Paulo: Cultura Acadêmica, 2006.

INSTITUTO ARTE NA ESCOLA. Arte, escola e cidadania. Umprêmio e seus premiados. São Paulo:Cultura Acadêmica, 2006.

ZAMBONI, Silvio. A Pesquisa em Arte. Um paralelo entre arte e ciência. Autores Associados.Campinas, 1998. 